\title{
Realization of Agricultural Machinery Equipment Management Information System Based on Network
}

\author{
Ling Ma, Academic Affairs Office of Chongqing Institute of Technology, Chongqing, China \\ Mohammad Ikbal, Lovely Professional University, Punjab, India \\ (iD) https://orcid.org/0000-0001-6148-1555
}

Korhan Cengiz, Trakya University, Turkey

\begin{abstract}
In order to study the role of information technology in the promotion of agricultural development and information in today's social and economic development of the most important strategic impact, on the basis of modern management, this paper investigates and studies the existing agricultural machinery management information system through the application of grey theory, information system engineering, information system utility, and other theories. The results show that a new agricultural machinery equipment management information system is developed through PHP and Mysql databases, and the system data is summarized and analyzed to obtain agricultural machinery management information. Through the experiment, the authors found that ordinary users can inquire about agricultural policies and science and technology through the internet and can also inquire about the scientific and technological schemes of various agricultural development processes.
\end{abstract}

\section{KEYWORDS}

Information Technology Application, Mathematical Model, Modern Agriculture, Network Platform Construction

\section{INTRODUCTION}

China is a big agricultural country, and its cultivated land accounts for about $10 \%$ of the world's cultivated land, providing about $30 \%$ of the world's food. In the course of more than 20 years, China has gradually entered the stage of modernization. Facing the growth of population and the acceleration of globalization, the modernization of agriculture is essential. To improve the international competitiveness of agriculture and give priority to the development of rural economy is the main task of China at this stage. China should attach importance to the development and research of high and new technology, better realize the goal of agricultural modernization and improve the competitiveness.

The development of agriculture in foreign countries has mainly experienced three stages: 1970s, 1980s and 1990s.Before the 1980s, it mainly focused on the collection of agricultural data and the expansion of agricultural information database. Since the 1990s, the focus has shifted to the processing and application of information, and the development of agriculture through the use of information

This article published as an Open Access article distributed under the terms of the Creative Commons Attribution License (http://creativecommons.org/licenses/by4.0/) which permits unrestricted use, distribution, and production in any medium, provided the author of the original work and original publication source are properly credited. 
systems. The agricultural development of European and American countries is relatively rapid and has entered the stage of industrialization. Most family farms, rural growers and farms in the United States are equipped with electronic equipment. Through the network platform to obtain the latest agricultural policy, machinery and equipment, weather forecast and other information. You can also sell or purchase raw materials of crops through the network platform. You can know the latest market price and supply-demand relationship at home. Improve agricultural production efficiency (Heng, Z. 2020).The United States has formed a three-level agricultural information platform composed of States, regions and countries. All departments work together to provide farmers with efficient and accurate data to facilitate agricultural production. For example, the U.S. Department of agriculture has established an agricultural information dissemination system, which receives agricultural information and publishes market price and agricultural technology data on time. The data are collected through the Agricultural Statistics Bureau and then transmitted to farmers by computer transmission system (Qiang, Y. Caixia, G et al 2018). Japan's agricultural development is relatively backward, in the 1960s chose the computer agricultural technology reform, since then agriculture has been rapid development. Through computer technology to promote the development of agriculture, improve the enthusiasm of farmers in production, further stimulate the progress of Agricultural Technology (Wei, Y., Wang, X, et al 2018).We should speed up the process of agricultural development through information collection system and communication system. Japan has set up a special agricultural information system to disseminate new technologies, products and policies on agriculture, so as to achieve information popularization and resource sharing. Propaganda and education should be carried out in all aspects of production to promote the development of industrial chain and promote the progress of new agricultural economy. The level of machine income has also increased steadily, reaching about $20 \%$.China's agricultural equipment has been developing rapidly. Taking Zhejiang Province as an example, the agricultural facilities in the province are basically complete in the early 21 st century. According to incomplete statistics, there are about 68.25 million agricultural tractors, including large and medium-sized and small-sized ones, about 180000 transport equipment and about 1400 harvesters. In terms of crop production, there are 7.6 million tea processing machines and about 350 grain drying machines, with a total of 4.23 million tons of dried grains. In terms of agricultural sowing, there are 195 mechanized rice transplanters, 400000 irrigation machines and 20000 spraying machines. At the beginning of the 21st century. By the end of the 20th century, more than 8.5 million mu of agricultural machinery had been used in the province. In addition, crop cultivation and mechanical facilities have also formed a certain scale. There are mainly two kinds of cultivation facilities, namely, plastic multi span greenhouse and plastic simple greenhouse, occupying more than 2 million and 600000 square meters respectively in the province, and there are more than 200 greenhouse mechanical facilities (Li, C., Tang, Y. et al 2020).In recent years, the level of Agricultural Mechanization in China is developing continuously, but it is still far behind the technical level of developed countries. It will take a long time to catch up with the development pace of developed countries(Duau, J., Zhang, L. et al 2018).

According to the survey, there are still many problems in agricultural machinery information management in China. Therefore, based on the collected data of agricultural machinery in various countries, this paper analyzes the current development situation, puts forward corresponding measures for the further improvement of agricultural machinery technology level, and constantly updates the information of agricultural mechanization management information system, and analyzes the necessity of establishing a new agricultural machinery equipment information system. Then, based on the existing management theory, the information management system technology, decision support system technology and concurrent engineering technology are integrated to create a new model. Finally, based on Linux operating system, Apache, a relational database management system named MySQL and a hypertext domain processor PHP are selected to create a new platform for sharing agricultural machinery equipment information (Linlin, Qin, et al 2015). 
Rest of the literature is organized with due consideration of the format of the journal. In next section authors have discussed few important literatures authors have gone through for their understanding the current scope of work and contribution made by authors across the globe in the concern field. In section three system models is proposed and discussed in detail with the help of relevant diagram, flow chart and explanations. Section four is dedicated for the analysis of the results of system implementation and it represents certain layout of the proposed model so that a clearer understanding of the model may be conveyed. In section five all the results are combined and a conclusion is presented with a future scope.

\section{LITERATURE REVIEW}

In article (Guo, Tiantian et al 2015) authors have proposed a novel data acquisition system along with smart monitoring and control system for agriculture facilities. The objective of their work was to promote the effectiveness and efficiency of product. The propose system includes, data collection system, wireless transmission network and sensor configuration, programmed control function of greenhouse with the help of sensor nodes and smart agriculture irrigation function based on frequency conversion. They have received good response after implementing this function in Tianjin. With their efforts farmers have achieved good ecological and economic benefits.

In article (Hongyan, Wu 2015), authors have discussed and designed a management system for agriculture. The purpose of this system was to bring agricultural digitization and to put forward a complete system dedicated for the said purpose. They have given 10 particular technologies for digitization of spatial information management portal at micro level.

In another referred article (Guozhong et al 2006) authors have proposed J2EE three tier architecture and struts framework for the development of enterprise information system more effectively and to improve the robustness of the proposed application. For helping data storage effectively the optimization of database was carried out. For observing the maintainability, extendibility and reliability of the proposed system the authors have conducted various test for developing the application framework based on information system.

In (ZHAO, Fei, et al 2006) the authors have made an analysis of different functions index, manufacturers and prices of agriculture machinery for providing better understanding of almost every kind of agriculture machinery to the farmers as well as agriculture machinery administrative department, particularly for Shanxi province. They have achieved that with the help database management language Access, and by object-oriented programming language. By virtue of their efforts farmers can plan and purchase most appropriate equipment for their efficient use and optimum price and administration can take necessary action regarding the purchase and sell of equipment.

In (He, Yong, et al 2005) the authors have proposed a system where urgent and critical problems related to the agriculture and farming may be shared, discussed and addressed. This system was developed on Web GIS using programming language JAVA by combining traditional MIS with web GIS.

In (Weiwei, Li et al 2009) the authors have proposed agriculture information system based on JSP and discussed its pros and cons in detail. In (Shi, De Lin. 2014) the authors have proposed an intelligent agriculture management system based on IoT. With the help of their model the problems associated with the farming may be discussed on a public forum with less time and more appropriately.

\section{SYSTEM DESIGN METHOD}

The integrated information subsystem of agricultural machinery and equipment mainly consists of five parts, as shown in Figure 1. The technical level, relevant policies, journals and discussion platform of agricultural machinery are introduced in detail (Lan-hua, et al 2011). 
Figure 1. Agricultural machinery equipment integrated information subsystem module diagram

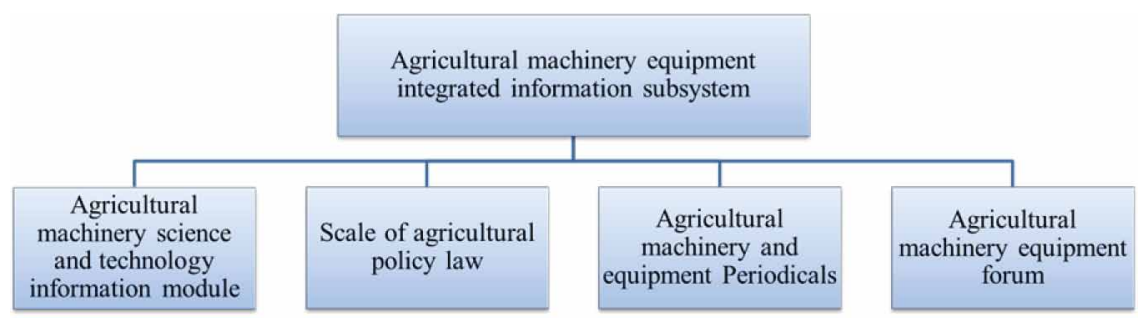

\subsection{Integrated Subsystem of Agricultural Machinery and Equipment}

The subsystem has a lot of data information and can be automatically updated. In order to relieve the pressure of the database system, it needs to clean up the data from time to time. In the management of data information, the system should follow the following steps: first, determine whether the operation meets the conditions. If the operation is approved, the information can be added, otherwise, it cannot (Ruiz-Garcia, et al 2010) modify, add or delete the information in the database. In the process of user operation, the system will automatically record the information and store it in the system log. This can be shown in Figure 2 (Sharma, Ashutosh et al 2010).

\subsection{Subsystem Module}

1. Agricultural machinery science and technology information module.

Formation of this module can be divided into three parts: on the one hand, it introduces the establishment, examination and approval, implementation and implementation process of the project; on the other hand, it updates the research results, technical breakthroughs and advantages and disadvantages analysis of agricultural machinery and equipment at home and abroad in real time; in addition, it also tells about the development planning and estimated demand of agricultural machinery and equipment (Jan, M., \& Ahmad, H 2020).

2. Agricultural policy and regulation module.

Law plays a more and more important role in the current market economy environment. Both social and economic activities should abide by laws and regulations. In other words, law restricts

Figure 2. Flow chart of information maintenance

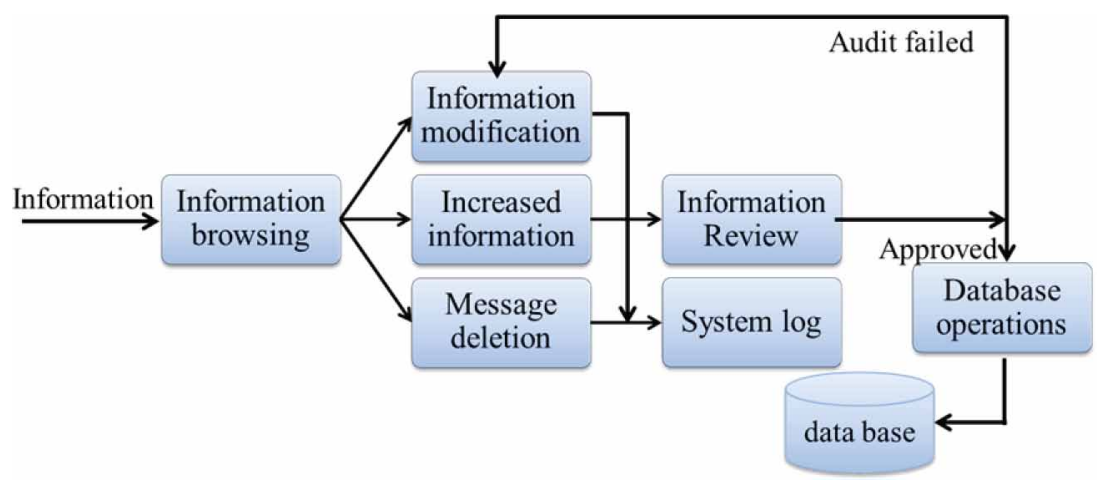


the occurrence of bad behavior in social and economic activities. All behaviors of the market must be based on abiding by the law. Therefore, market economy is equal to legal economy, and market agriculture is also called legal agriculture. China's accession to WTO creates better conditions for China's economic development, but it also poses a threat to domestic enterprises. Therefore, in agriculture, the government should formulate protection policies to ensure the steady development of agriculture and protect the interests of farmers.

Therefore, the module is committed to popularizing relevant policy knowledge, so that people can understand the support and protection of agricultural science and technology, resources, intellectual property rights and other aspects of the country (Rathee, Geetanjali, et al. 2020, Poongodi, M., et al.2020).

3. Agricultural machinery and equipment Periodicals.

Agricultural machinery equipment journals mainly involve the information of machinery itself, traffic safety, technology development and operation about the agricultural machinery itself, it will tell about the update and maintenance of products in terms of traffic safety, it will collect relevant real events to remind drivers that they must pass the examination, have the ability to drive agricultural machinery, and regularly review the safety of the equipment; in the development and improvement of agricultural machinery, analyze the recent development trend of agricultural machinery and the industry; in terms of the operation of agricultural machinery and equipment, It is necessary to popularize important information related to agriculture to the public, such as subsidy policies, tax reduction and exemption measures, etc (Hibino, H., Kubo, N et al. 2019, Dogra, Jyotsna, et al 2020).

\section{Agricultural machinery equipment forum.}

BBS is a platform for users to exchange information by using network technology, also known as electronic bulletin board. Users can express their opinions while seeking help from others. The product information of agricultural machinery equipment needs to be spread, and forum is the best choice. In the forum, users can exchange experiences and share gains and losses, so as to further promote the development and prosperity of agriculture (Liu H., Jia H., Liu Y., et al. 2019)

\subsection{Design of Agricultural Machinery Equipment Forum}

1. Structure design of online forum.

The forum should manage users, forums and messages. For users, it is necessary to set up functions such as login, registration, cancellation and modification of personal data. In terms of the forum we should pay attention to update the new forum and sub forum, delete the original forum, and publish and modify the article. At the same time, we can't ignore the reply and notification function of the forum (Poongodi, M., et al 2019). In the message aspect, the user can leave a message by himself and leave a message to others. In the message module, the user can reply to a new message (Liu, Jichao, and Kun Li, 2020).

The structure of the Forum on the Internet is described in Figure 3.

2. Design of online forum database.

Online forum includes six different tables, including user table, online user table, forum information table, sub forum information table, article information table and message information table. The user table includes the user's personal information and other information; the online user 


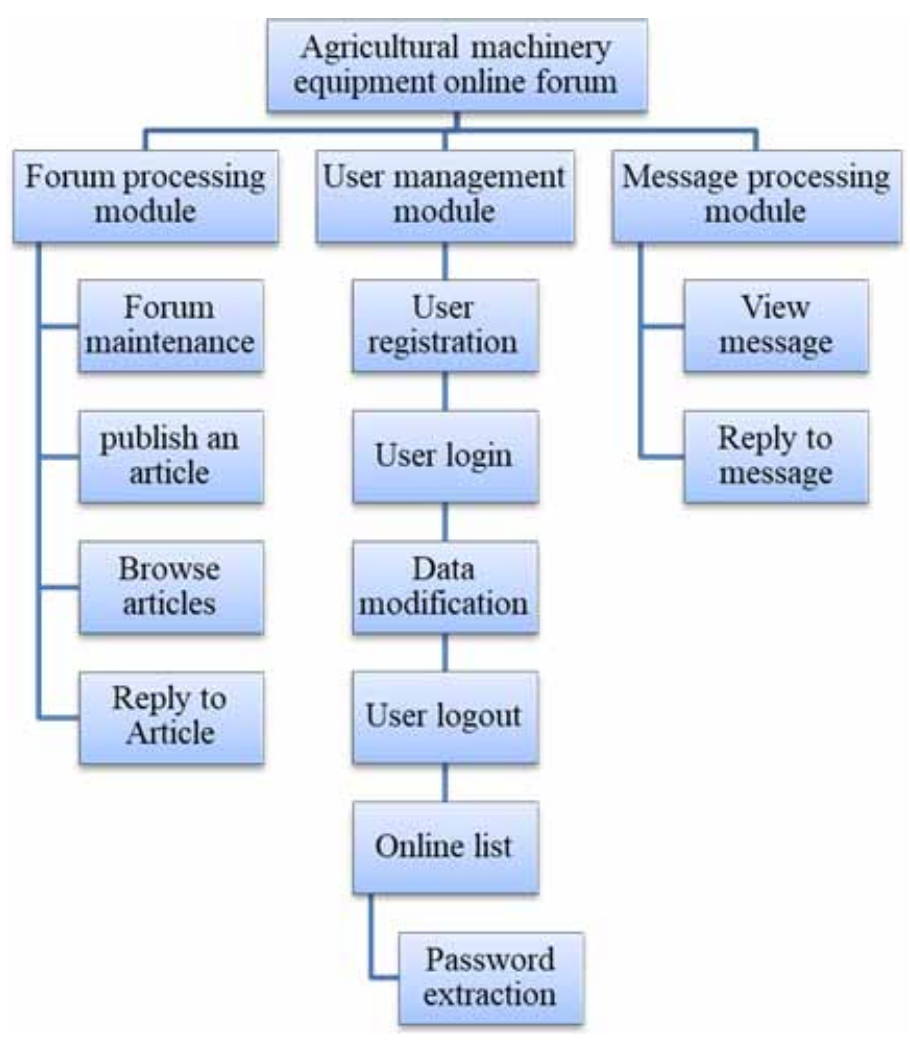

table is only for online users, which records the information of online users; the forum information table involves the information of the Forum; the sub forum describes the detailed information of the sub forum, including some codes; the article information table records the information of the articles and other contents of the forum; Record the message form of the user (Yang, Bo 2020).

3. Design and implementation of online forum process.

The design and experiment of online forum process cannot be separated from the support of users. The user ventilation is composed of five aspects: registration and login in the forum, display of post title, post content and post published in reply. See Figure 4 for details (Joannou, Demetrios, et al 2020).

\section{ANALYSIS OF THE RESULTS OF SYSTEM IMPLEMENTATION}

\subsection{System Implementation}

The management and operation of agricultural machinery and equipment is shown in Figure 5, which mainly depends on the network. According to its different functions, it can be divided into three different aspects: agricultural machinery equipment market information, agricultural machinery equipment decision-making and prediction and agricultural machinery equipment general information. Users can perform different operations in the menu according to their own identity (Xiao, Jie 2020). 
Figure 4. Online BBS flow chart

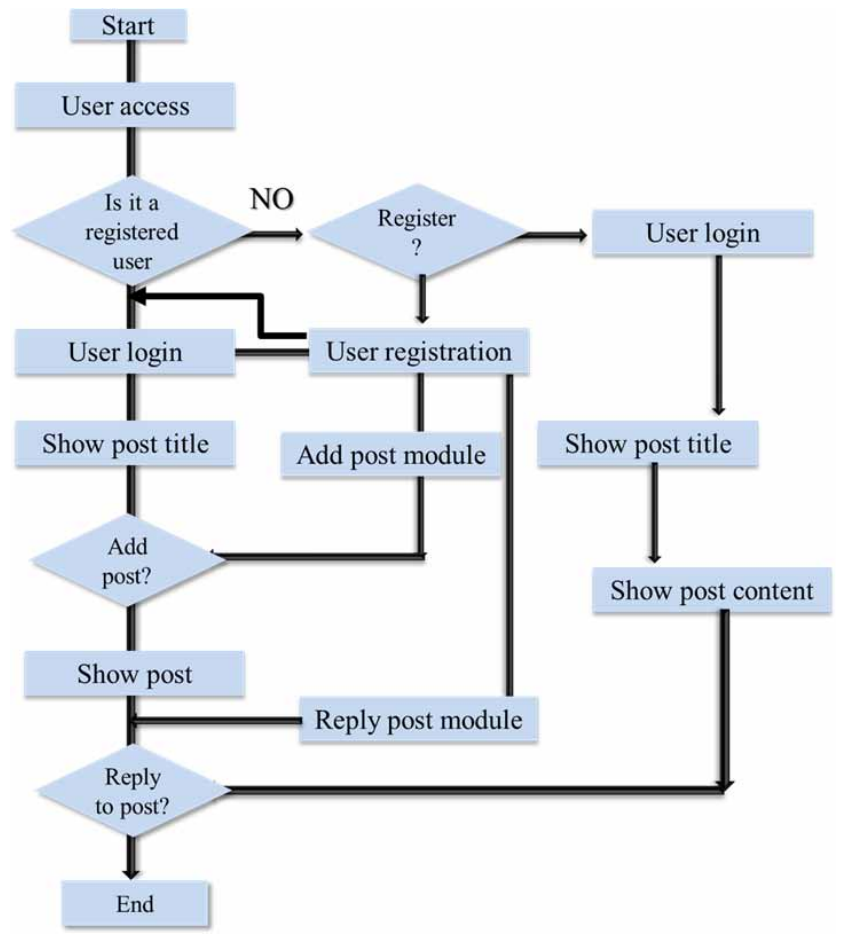

Figure 5. Main interface of system operation

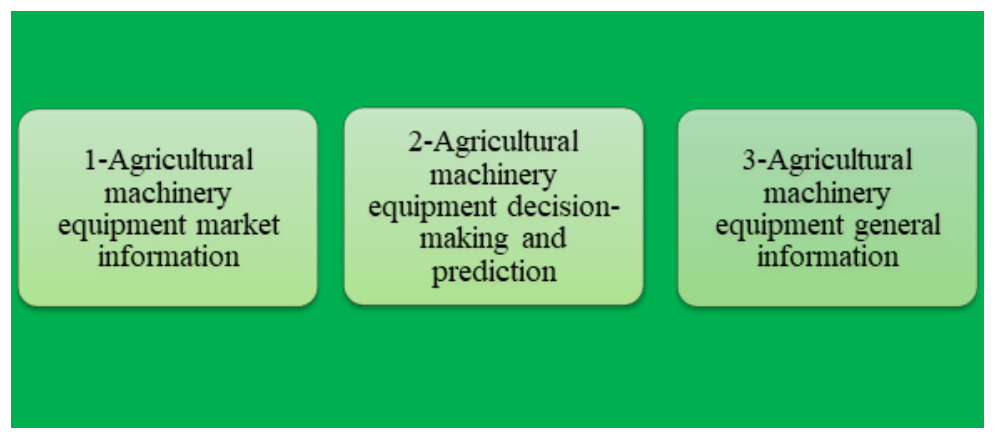

In the home page, it mainly shows the three different aspects: market information is composed of industry information, business opportunities and enterprise directory; decision making and forecasting are composed of statistical management; and the overall information needs the cooperation of science and technology policy and forum.

\subsection{Integrated Information Subsystem of Agricultural Machinery and Equipment}

"Agricultural machinery equipment integrated information subsystem" includes four different modules, including agricultural machinery science and technology, policies and regulations, agricultural machinery journals and agricultural machinery science and technology. These four services are for farmers and enterprises. In terms of science and technology, it is necessary to introduce science and technology, promote science and technology, and identify science and technology, and these 
technologies include loosening soil, farming, sowing, weeding, fertilization, sprinkler irrigation, transportation, storage, processing and other mechanical equipment. It is necessary to analyze the current situation and future of these equipment, so as to promote its faster and better development (see Figure 6 for some interfaces (Li, Hongxing, et al 2020).

There are more than 1000 policies, laws and regulations related to agriculture. At the same time, all kinds of materials before, during and after production can be inquired and involved (some interfaces are shown in Figure 6).

The Journal of agricultural machinery emphasizes the spirit of the conference and the policy documents on science and technology. It will be published regularly, taking into account the interests of the government (see Figure 6 for some interfaces).

Agricultural machinery forum allows users and people seeking information to exchange and communicate here, so as to find problems and solve problems (see Figure 7 for some interfaces).

\subsection{Agricultural Machinery Equipment Market Information Subsystem}

"Agricultural machinery equipment market information subsystem" mainly considers the user side, to make the user experience as the goal, to satisfy the user, and to promote information security. The following two aspects of "information query" and "demand information" are described in detail (Shenbagavalli, S., et al 2020).

Users need to click the "supply information" button to understand the specific situation (realized by step 1 in Figure 8) to get a new link. This link is the specific information introduction of

Figure 6. Interface of the integrated information subsystem

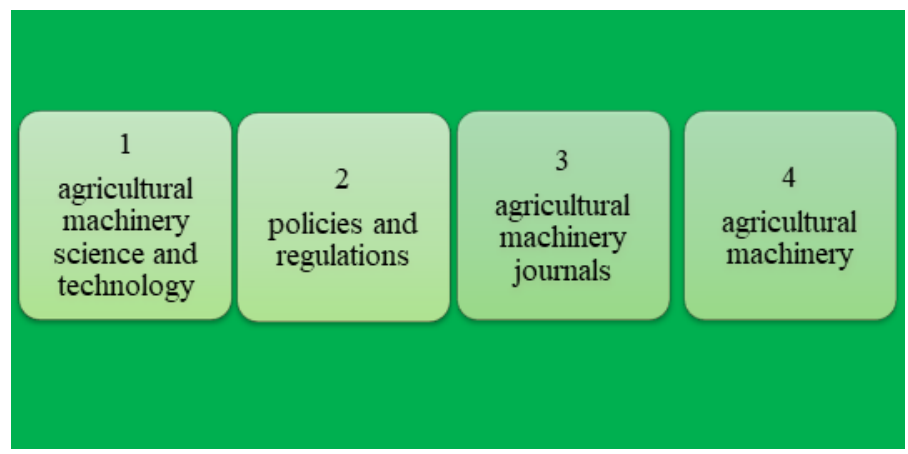

Figure 7. BBS interface of agricultural machinery

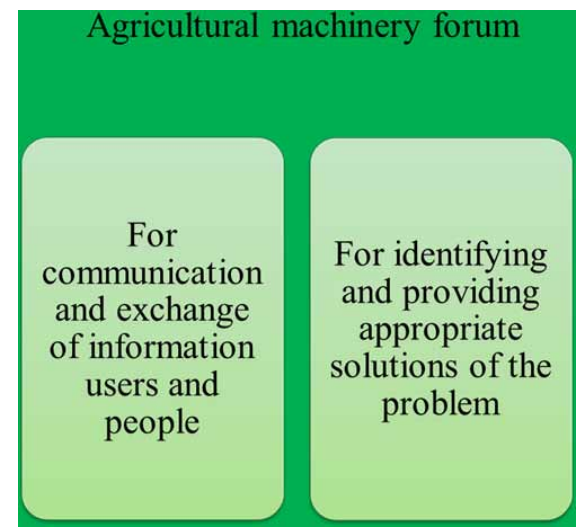




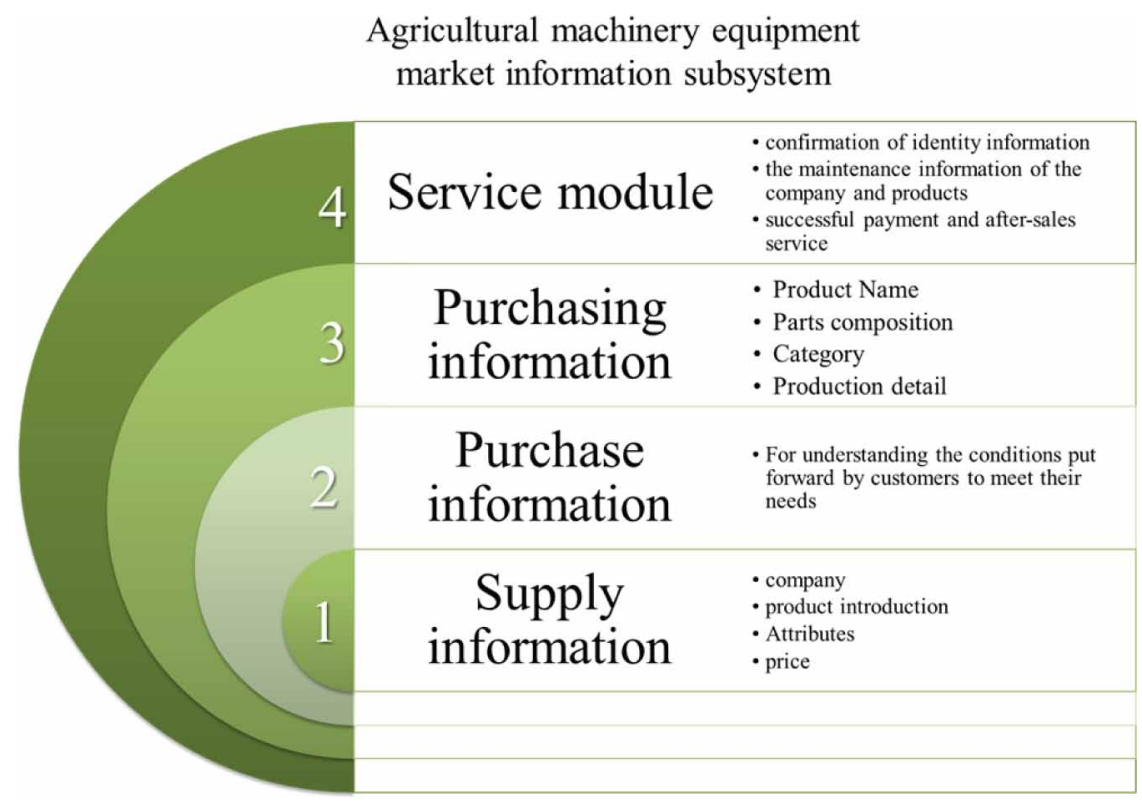

agricultural machinery and equipment products, including which company it comes from, its basic product introduction, its attributes, and the price for reference, And the website's browsing rate is more attractive is the product picture. Providing pictures can help customers understand the products more intuitively and vividly. If the customer can find out more about the product by clicking on the product name (Singh, Sukhpal et al 2020).

The specific items of "purchase information" (realized by step 2 in Figure 8) can also be browsed by manufacturers of agricultural machinery or service providers. By browsing this page, you can understand the conditions put forward by customers to meet their needs. "Purchasing information" mainly includes the product name, parts composition, category, standard, production unit, production address, email address, website, production place, etc. If they have enough resources to meet the requirements of farmers, they can communicate with them.

Users can learn about the service process of the enterprise by clicking the options they are interested in. The service module covers the confirmation of identity information, the maintenance information of the company and products, as well as the successful payment and after-sales service.

When clicking to enter the enterprise system, users need to verify their own identity first, and then they can enter the information system and start the next operation. If there is provision that nonregistered people cannot enter the system, then it reflects the enterprise's rigor in safety management.

Click on "product maintenance" to add (realized by step 2 in Figure 9), delete and modify (realized by step 3 in Figure 9) and other steps. When the company is ready to launch a new product, it first needs to be checked and approved by the staff who maintain the system, which shows that the product information is accurate. If the company makes certain modifications and adjustments to the products, it still needs to be re identified by the designated department.

In order to avoid improper operation of customers, careless deletion of products or other important information related to products, the enterprise has set up a second prompt.

The form of enterprise system management module is similar to the above-mentioned service module. The system management module package adds a link to manage the system log.

When the administrator carries out system maintenance, he / she should first verify his / her identity (realized by step 1 in Figure 10). After entering the system maintenance page, he / she can 
Figure 9. Part of the "enterprise service module" interface

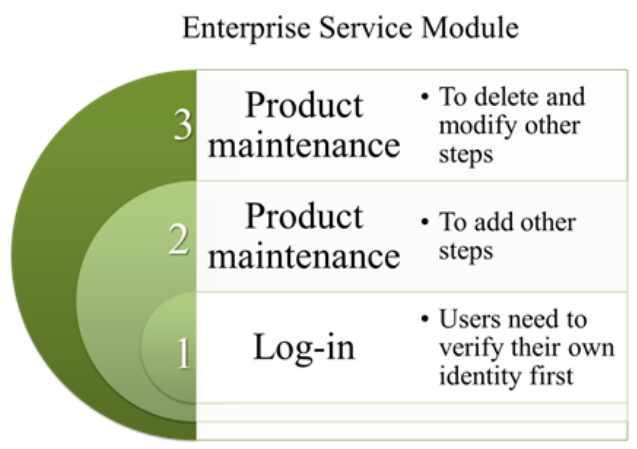

click "search function" (implemented by step 2 in Figure 10) to accurately target a specific company. The diagram also shows the confirmation option operation for the enterprise service module.

For important operations, the enterprise also has a second prompt pop-up box, such as whether to confirm to modify the audit, etc.

\section{CONCLUSION}

In this paper, the existing agricultural machinery management information system is investigated and studied. By referring to the previous relevant literature and combining with the existing developed technology, a new agricultural machinery equipment management information system is developed through PHP and MySQL database. The system adds network elements through innovation.

Some specific achievements are shown as follows:

1. With the existing management system as the theoretical foundation, through the integration of MIS technology, DSS technology and CE technology, and using network technology to innovate a more perfect and more timely agricultural machinery management system.

2. Through the existing resources and network elements to create a new platform of agricultural machinery equipment system management.

Figure 10. Interface of "system management module"

System Management Module

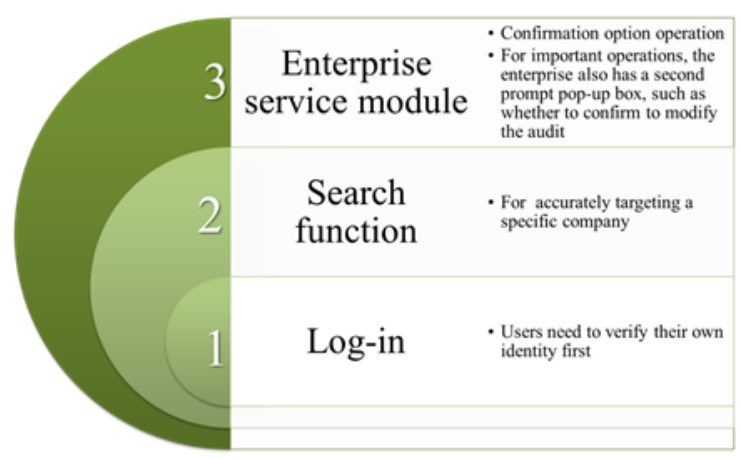


3. Collecting various forms of mathematical methods to form a huge model base for use, including the famous Markov chain joint prediction method and the artificial neural network prediction method mentioned in this paper, and the mathematical model involves rough set factor analysis. In addition, it also makes a thorough analysis on the aspects that may be involved in the future development of agricultural machinery, such as the demand of agricultural machinery, the value and use value of agricultural machinery.

The level of agricultural mechanization in China is constantly developing, but it still lags far behind the technical level of developed countries. It will take a long time to catch up with the pace of development in developed countries. 


\section{REFERENCES}

Dogra, J. (2020). Brain tumor detection from MR images employing fuzzy graph cut technique. Recent Advances in Computer Science and Communications, 13(3), 362-369.

Duau, J., Zhang, L., Zhang, Z., Zhao, J., \& Jiang, Y. (2018). Research on Automatic Steering System of Agricultural Machinery Based on Fuzzy Neural Network. In 2018 2nd IEEE Advanced Information Management, Communicates, Electronic and Automation Control Conference (IMCEC). IEEE.

Guo, T., \& Zhong, W. (2015). Design and implementation of the span greenhouse agriculture Internet of Things system. In 2015 International Conference on Fluid Power and Mechatronics (FPM). IEEE. doi:10.1109/ FPM.2015.7337148

Guozhong, Y. C. T. Z. G. (2006). Developing Information Management System for Agricultural Machinery Enterprise with Three-tier Architecture Based on J2EE. Nongye Jixie Xuebao, 7.

He, Y., \& Yu, X. (2005). Design and implementation of agricultural mechanization information management system based on Web GIS. Nongye Jixie Xuebao, 36(10), 88-90.

Heng, Z. (2020). Agricultural machinery information management system based on intelligent express terminal access scheme. Journal of Agricultural Mechanization Research.

Hibino, H., Kubo, N., Matsumoto, Y., Kimura, M., \& Mizukami, Y. (2019). Modelling and simulation of agricultural production system of multiple-crop rotation based on iot cultivated field information. [in Japanese]. Transactions of the JSME, 85(872), 18-00148. doi:10.1299/transjsme.18-00148

Hongyan, W. (2015). Design and Implementation of Agricultural Information Service Platform based on Resource Integration. In 2015 Conference on Informatization in Education, Management and Business (IEMB-15). Atlantis Press. doi:10.2991/iemb-15.2015.171

Jan, M., \& Ahmad, H. (2020). Image features based intelligent apple disease prediction system: Machine learning based apple disease prediction system. International Journal of Agricultural and Environmental Information Systems, 11(3), 11. doi:10.4018/IJAEIS.2020070103

Joannou, D. (2020). Realizing the role of permissioned blockchains in a systems engineering lifecycle. Systems, $8(4), 41$.

Lan-hua, Z. (2011). Design and Implementation on Agricultural Multimedia System Platform. Anhui Nongye Kexue, 6, 224.

Li, C., Tang, Y., Wang, M., \& Zhao, X. (2020). Agricultural Machinery Information Collection and Operation Based on Data Platform. In IEEE International Conference of Safety Produce Informatization. Qilu University of Technology.

Li, H., Smith, C. D., Cohen, A., Wang, L., Li, Z., Zhang, X., Zhong, G., \& Zhang, R. (2020). Implementation of water safety plans in China: 2004-2018. International Journal of Hygiene and Environmental Health, 223(1), 106-115. doi:10.1016/j.ijheh.2019.10.001 PMID:31606406

Linlin, Q. (2015). Implementation of IOT-based greenhouse intelligent monitoring system. Nongye Jixie Xuebao, 46(3), 261-267.

Liu \& Li. (2020). Design and Implementation of Computer Aided Equipment Management Information System. Academic Press.

Liu, H., Jia, H., \& Liu, Y. (2019). Collection System of Soil Moisture Information Based on ZigBee and GPRS. Agricultural Biotechnology, (6).

Poongodi, M. (2020). Prediction of the price of Ethereum blockchain cryptocurrency in an industrial finance system. Computers \& Electrical Engineering, 81, 106527. doi:10.1016/j.compeleceng.2019.106527

Poongodi, M., Hamdi, M., Sharma, A., Ma, M., \& Singh, P. K. (2019). DDoS Detection Mechanism Using TrustBased Evaluation System in VANET. IEEE Access: Practical Innovations, Open Solutions, 7, 183532-183544. doi:10.1109/ACCESS.2019.2960367 
Qiang, Y., Caixia, G., Bin, L. V., \& Chao, S. U. (2018). Research on the remote management information system of agricultural machinery. Agriculture Network Information.

Rathee, G., Sharma, A., Kumar, R., Ahmad, F., \& Iqbal, R. (2020). A trust management scheme to secure mobile information centric networks. Computer Communications, 151, 66-75. doi:10.1016/j.comcom.2019.12.024

Ruiz-Garcia, L., Steinberger, G., \& Rothmund, M. (2010). A model and prototype implementation for tracking and tracing agricultural batch products along the food chain. Food Control, 21(2), 112-121. doi:10.1016/j. foodcont.2008.12.003

Sharma, A., Ansari, M. D., \& Kumar, R. (2017). A comparative study of edge detectors in digital image processing. In 2017 th International Conference on Signal Processing, Computing and Control (ISPCC). IEEE. doi:10.1109/ISPCC.2017.8269683

Shenbagavalli, S. (2020). Design and Implementation of Smart Traffic Controlling System. International Journal of Engineering Technology Research \& Management, 4(4), 28-36.

Shi, D. L. (2014). Research and Design of Intelligent Agriculture Management System Based on the Internet of Things. In Applied Mechanics and Materials (Vol. 687). Trans Tech Publications Ltd.

Singh, S., Chana, I., \& Buyya, R. (2020). Agri-Info: Cloud based autonomic system for delivering agriculture as a service. Internet of Things, 9, 100131. doi:10.1016/j.iot.2019.100131

Wei, Y., Wang, X., Wang, R., \& Gui, Y. (2018). Design and implementation of agricultural production management information system based on webgis. Nongye Gongcheng Xuebao, 34(16), 139-147.

Weiwei \& Xiuli. (2009). Agricultural Inforamtion System Based on JSP. Agriculture Network Information, 12.

Xiao, J., \& Jing, T. L. (2020). Design and Implementation of Intelligent Temperature and Humidity Monitoring System Based on ZigBee and WiFi. Procedia Computer Science, 166, 419-422. doi:10.1016/j.procs.2020.02.072

Yang, B. (2020). Research on Network Database Laboratory Instrument Management Information System Based on Content Query. $M S \& E$, 740(1).

Zhao. (2006). Research on Information Administrative System for Agricultural Machinery in Shanxi Province. Shanxi Nongye Daxue Xuebao, 1. 